\title{
Racionalidades e Complexidades em Planejamento e Gestão de Projetos
}

\author{
http://dx.doi.org/10.21527/2237-6453.2019.49.44-58 \\ Recebido em: 8/11/2017 \\ Aceito em: 23/5/2019
}

\section{Cristiano Desconsi ${ }^{1}$}

\begin{abstract}
RESUMO
As últimas décadas foram marcadas pela emergência das teorias da complexidade e, paralelamente, pela construção das abordagens territoriais do desenvolvimento, processo que colocou em questão o desafio de repensar os procedimentos mais comuns utilizados na área de planejamento e gestão de projetos construídos segundo os pressupostos da racionalidade científica. Situado nessa temática, este artigo reflete sobre a relação entre a racionalização do processo de planejamento e gestão de projetos e a complexidade do desenvolvimento territorial. Para tal, faz uso da análise bibliográfica destacando a relevância da abordagem sistêmica para examinar sistemas complexos, investigando, por fim, alguns elementos de experiências com projetos de crédito rural a agricultores familiares e projetos sociais que fazem uso do Quadro Lógico como instrumento de planejamento e gestão. $O$ texto sugere, por essa via, que existem possibilidades de aprimoramento dos procedimentos e técnicas racionais de planejamento e gestão de projetos para o trabalho em realidades complexas expressas nos territórios, quando se rompe com a unilinearidade das ações interventivas e se assume novas práticas de construção do conhecimento.
\end{abstract}

Palavras-chave: Projetos. Racionalidades. Complexidade. Desenvolvimento.

\section{RATIONALITIES AND COMPLEXITIES IN PLANNING AND MANAGEMENT OF PROJECTS}

\begin{abstract}
The last decades were marked by theemer gence of complexity theories and, at the same time, the construction of territorial approaches to development, a process that hás challenged the challenge of rethinking them ost common procedures used in the planning and management of projects built according to the assumptions of scientific rationality. Based on this theme, this article reflects on the relationship between the rationalization of the project planningand management processand the complexity of territorial development. To this end, it makes use of bibliographic analysis highlighting the relevance of the systemic approach to examining complex systems, finally examining some elements of experiences with rural credit projects to family farmers and social projects that make use of the Logical Framework as na instrument of planningand management. The texts uggests, therefore, that there are possibilities for improving the procedures and rational techniques of planning and project management for the work in complex realities expressed in the territories, when it breaks with the unilinearity of the interventionactions and if new construction practices are assumed of knowledge.
\end{abstract}

Keywords: Projects. Rationalities. Complexity. Development.

\footnotetext{
${ }^{1}$ Doutor em Ciências Humanas (Antropologia) pela Universidade Federal do Rio de Janeiro (UFRJ). Professor do Centro de Ciências Agrárias da Universidade Federal de Santa Catarina (UFSC). crdesconsi@gmail.com
} 
Este texto tem como objetivo discutir algumas controvérsias da racionalização do processo de planejamento e gestão de projetos na complexidade do desenvolvimento territorial. A emergência das teorias da complexidade, estabelecida nas últimas décadas, permitiu a construção de abordagens teóricas e metodológicas com maior capacidade de apreensão da realidade, sobretudo em sistemas sociais, econômicos, biológicos que apresentam alta dinamicidade (SILVA NETO, 2004). Essa emergência corrobora para a construção de novas abordagens territoriais do desenvolvimento, as quais assumem os territórios como sistemas complexos, exigindo um repensar nos conceitos, procedimentos e instrumentos utilizados para as ações de intervenção sobre os territórios (BACELAR, 2009; SEPUELVEDA, 2005; DESCONSI, 2018).

Algumas correntes das teorias da complexidade, entretanto, condenam os procedimentos racionais construídos pela ciência que dão base para a maior parte dos procedimentos de ações e intervenção (SILVA NETO; BASSO, 2010). Se a crítica é pertinente, entende-se que é possível estabelecer convergências entre as formulações das teorias da complexidade e reformulação dos procedimentos e práticas racionais mais comuns utilizadas nas ações de promoção do desenvolvimento. Esse é o objeto de reflexão do presente artigo, o qual está dividido em três partes: na primeira trata do planejamento e gestão de projetos e as realidades complexas. Isso se faz em duas frentes: fazendo uma sucinta caracterização da emergência do paradigma da complexidade e sua relação com a racionalidade, para em um segundo momento refletir as modificações conceituais, metodológicas utilizadas em planejamento e gestão de projetos, sobretudo na forma de tratar das incertezas e riscos. A segunda seção apresenta a importância da perspectiva sistêmica para tratar de sistemas complexos, dando ênfase para a criação e adequação das unidades de análise do desenvolvimento e para o planejamento estratégico articulados com instituição de projetos específicos em tais unidades. A terceira seção reflete a respeito do desafio de como os instrumentos de planejamento e gestões de projetos possam ou não ser adaptados para dar conta de sistemas complexos. Faz-se isso tratando de dois exemplos práticos, sem a preocupação de aprofundamento sistemático. O primeiro referente ao confronto de racionalidades distintas - entre agentes bancários/técnicos e agricultores familiares, que se manifesta no momento do planejamento e efetivação de projetos de investimento produtivo. $O$ segundo assinala como o instrumento do Marco Lógico subsiste nos dias atuais devido a sua adaptação e complementaridade com outros procedimentos para dar conta de realidades complexas.

\section{O PLANEJAMENTO E GESTÃO DE PROJETOS E AS REALIDADES COMPLEXAS}

As teorias da complexidade desenvolvidas nas últimas décadas dialogam com as novas abordagens sobre o desenvolvimento, tendo em vista que ambas buscam superar as limitações das teorias racionalistas e mecanicistas. Esta seção observa como as discussões recentes sobre o desenvolvimento territorial demandaram o aprimoramento das metodologias e técnicas de planejamento e gestão de projetos, especialmente para fazer frente às incertezas e riscos e adoção de multilinearidade como pressuposto dos processos de desenvolvimento. 


\section{A Complexidade do Desenvolvimento Territorial}

Os procedimentos adotados em processos de planejamento e gestão de projetos têm como base o conhecimento científico, o qual fornece os pressupostos e a base metodológica para sua efetivação. Observando os modelos convencionais de elaboração de um projeto, por exemplo, trabalha-se com os princípios da redução e isolamento dos elementos, mobilizando um conhecimento disciplinar sobre os quais se quer intervir ou modificar. O objeto da intervenção é trabalhado pelo princípio da causa-efeito que fundamenta o encadeamento das etapas do ciclo de um projeto, supondo que por essa via é possível controlar todos os elementos para chegar a determinados resultados (ARMANI, 2004; PFEIFER, 2010). Essa aplicação tem como base a perspectiva analítica ou mecanicista, cujo pressuposto é a racionalidade que estabelece o cálculo, a previsibilidade do planejamento das ações para ter certeza dos fins a serem alcançados no futuro. Tal perspectiva marcou a ciência moderna desde seu advento até o fim do século 20 e forneceu a base dos procedimentos mais comuns em planejamento e gestão de projetos.

O avanço da ciência, entretanto, sobretudo no século 20, apontou as limitações dessa concepção científica, permitindo que em diferentes áreas do conhecimento emergissem as chamadas teorias da complexidade. Muitos autores sugerem que a complexidade configura-se como um novo paradigma científico (nos termos formulados por Thomas Khun), pois demarca a construção de um novo quadro epistemológico que orienta a reformulação de abordagens teórico-metodológicas atravessando as várias áreas do conhecimento, inclusive exigindo a remodelação das próprias fronteiras disciplinares (BASSO; DELGADO; SILVA NETO, 2003).

De qualquer modo, se a ciência fornece os fundamentos para o enfrentamento dos desafios sociais, econômicos e ambientais, seu potencial mostra-se limitado diante das transformações produzidas pelo desenvolvimento da própria sociedade. Segundo as novas perspectivas científicas fundadas no paradigma da complexidade, para dar conta desse desafio faz-se necessário uma transformação na própria ciência, tanto em suas abordagens teórico-metodológicas como também na postura dos detentores do conhecimento científico diante dos demais grupos sociais, de maneira que a ciência possa, assim, considerar adequadamente a complexidade dos processos de desenvolvimento sustentável (SILVA NETO; BASSO, 2010).

Uma das principais abordagens teóricas que influenciou a construção de novos métodos e técnicas na área de planejamento e gestão de projetos, certamente, foi a teoria dos sistemas ou abordagem sistêmica. Miguel (2010) salienta que ela: i) permite reconhecer as propriedades e a interação dinâmica entre os elementos de um conjunto; ii) possibilita organizar o conhecimento de modo a compreender e estudar conjuntos mais amplos e complexos; iii) permite uma linguagem científica unitária como suporte à integração dos procedimentos metodológicos dispersos entre áreas disciplinares. Segundo Bertalanffy (1976), a abordagem sistêmica tem como pressupostos: i) a interação entre os elementos de um sistema; ii) a complexidade como pressuposto do sistema; iii) totalidade, ou seja, o sistema é um conjunto de elementos que não podem ser com- 
preendidos unicamente por um elemento isolado, mas sempre em relação ao todo; iv) hierarquia existente entre os elementos do sistema e entre diferentes sistemas; v) organização - um sistema supõe a organização estrutural (seus limites, elementos constitutivos e canais de ligação) e funcional (fluxos, entradas e saídas).

Assim, distingue-se, de um lado, as abordagens analíticas, que pressupõem somente o resultado, trabalham na decomposição dos elementos do objeto complexo, são baseadas no conhecimento disciplinar especializado e focam nas variáveis controladas. E de outro lado, as abordagens sistêmicas que valorizam o processo, focam nas interações entre os elementos que constituem uma totalidade, apontam soluções múltiplas para análise e ação com base na interdisciplinaridade e multidisciplinaridade e visualizam contradições e variáveis não controláveis que marcam sistemas dinâmicos (BASSO; DELGADO; SILVA NETO, 2003).

Miguel (2010) e Basso (2000) observam que as duas perspectivas podem ser complementares, pois enquanto uma fornece uma visão pontual e focalizada em elementos localizados, a outra proporciona uma visão do conjunto estruturado e articulado e a relação de um objeto e seu entorno. Tanto para a análise quanto para a aplicação em ações planejadas, portanto, é comum a mobilização de elementos de ambas as perspectivas, como veremos adiante, tratando do planejamento e da gestão de projetos, conforme exemplificado na última seção deste texto.

A perspectiva sistêmica também permite tratar de sistemas cujo grau de complexidade é maior, tendo em vista a quantidade e os tipos de elementos que os interligam. Nesse aspecto, a perspectiva analítica apresenta limitações para apreender a complexidade, a ponto de muitas vezes simplesmente utilizar o próprio termo complexo para se referir ao conjunto de variáveis que não consegue apreender ou controlar na análise e nas ações aplicadas (MIGUEL, 2010).

Parece comum entre os autores a constatação de que o processo de desenvolvimento dos sistemas sociais, econômicos, biológicos implica um aumento gradativo dos elementos que constituem essa perspectiva, bem como o grau e número de interações e encadeamentos possíveis dentro e fora do sistema. Tal constatação sugere uma tendência à complexidade dos sistemas, ou dito de outra forma, a passagem de sistemas simples para sistemas complexos.

Não é por acaso que as limitações das abordagens analíticas para apreender esses sistemas complexos também se tornam evidentes quanto são adotadas abordagens do desenvolvimento sustentável que valorizam a escala local e a diversidade dos atores sociais e suas práticas produtivas e culturais. Ao tomar o território, o âmbito microssocial para análise e intervenção, mas percebendo-o como parte de um sistema mais amplo que perpassa a escala local, é possível perceber a multiplicidade de interações entre os elementos existentes no contexto territorial e os limites e as possibilidades de uma possível intervenção. Logo, as abordagens territoriais que emergem nas décadas recentes também contribuíram para trazer à tona situações de grande complexidade e a importância de adequação dos procedimentos de planejamento e gestão de projetos a serem utilizados como meios de promover o desenvolvimento territorial. 


\section{Gerir Incertezas e os Riscos}

Provavelmente uma das principais contribuições das teorias da complexidade para a área do planejamento e gestão de projetos é sua ênfase nas incertezas e riscos. 0 processo de planejamento e gestão de projetos pressupunha um conjunto de procedimentos racionais visando a controlar todas as variáveis que podem influenciar o alcance de um determinado resultado previsto. De alguma maneira, isso não era difícil na perspectiva analítica, pois seus procedimentos supunham ações de diagnóstico focalizadas nos elementos nos quais se pretendia intervir, supondo a existência de leis universais e dando pouca importância para o ambiente no qual seriam efetivadas. Nesse sentido, as incertezas são identificadas e são definidas estratégias visando a eliminá-las do processo e, com efeito, possibilitar o cálculo e previsão de resultados e mudanças esperadas.

As formulações dos teóricos da complexidade sugerem que analisar o desenvolvimento das sociedades implica o reconhecimento de que estas são estruturas dissipativas (auto-organizadas), abertas e que evoluem (PRIGOGINE, 1996). Sua constituição emerge fundamentalmente das interações locais de seus constituintes e que sua trajetória evolutiva não pode ser prevista, ao menos por meio de um planejamento centralizado eficaz. Também significa dizer que os métodos estatísticos construídos para calcular probabilidades são insuficientes para dar conta das especificidades e das mutações dos sistemas complexos (SILVA NETO; BASSO, 2010). Nesse sentido, o reconhecimento de que uma comunidade, um território é um sistema diverso e dinâmico de onde emergem novas interações e elementos que geram novas propriedades (PRIGOGINE, 1996), implica a assunção da incerteza como uma questão a ser gerida e não passível de ser controlada em plenitude, como supunha a prática científica tradicional. É nesses termos que os procedimentos utilizados em planejamento e gestão de projetos quando aplicados em sistemas complexos devem ser flexíveis e adaptáveis ao contexto e às mutações que ele apresenta.

Normalmente considera-se que a incerteza é determinada pela imprevisibilidade do comportamento de uma ou mais variáveis. Ela pode ser intrínseca do comportamento da variável, mas também ser originada pela falta de conhecimento que se tem sobre ela. No primeiro caso, trata-se da constatação de incertezas substantivas que não podem ser controladas, mas precisam ser geridas durante o processo. No segundo caso, há a possibilidade de procurar compreender melhor a variável em questão. Ao assumir, contudo, que as realidades sobre as quais se quer intervir são sistemas complexos pode-se incorrer em um problema que se refere ao tratamento das informações e do conhecimento sobre os sistemas complexos (BASSO; DELGADO; SILVA NETO, 2003). Em muitas experiências de planejamento de projetos, as organizações modularam procedimentos procurando ampliar a compreensão do contexto de atuação, muitas vezes elaborando extensos questionários aplicados ou outros procedimentos que demandavam tempo e grande quantidade de recursos. No momento seguinte, entretanto, enfrentaram a necessidade de processar esse volume de informações de modo a dar utilidade prática às etapas do projeto, algo que nem sempre era tão fácil. Assim, se por um lado, considerar todas as informações possíveis é uma condição importante para conhecer e encontrar soluções mais adequadas, por outro, a partir de certo nível de complexidade, esta gama 
de informações e conhecimentos pode-se tornar irracional, do ponto de vista da modulação em instrumentos de ação (como um projeto, por exemplo), com condições de concretizar a solução de determinados problemas.

Esse aspecto evidencia a importância de encontrar o ponto de equilíbrio na incorporação de procedimentos mais densos para compreender a complexidade, sem perder de vista a racionalidade que permite dar efetividade às ações em planejamento e gestão de projetos. É preciso, contudo, registrar que diferente da perspectiva analítica, as teorias da complexidade reconhecem que não é possível apreender a realidade tal como ela é, ou seja, os procedimentos de apreensão são sempre limitados, sobretudo porque os sistemas complexos são extremamente dinâmicos, o que implica o reconhecimento que estão em constante mudança em termos das modalidades de interações, elementos constituintes, grau e intensidade dos fluxos. Essa dinâmica, ainda que possa apresentar um determinado ordenamento, não permite pelos procedimentos racionais estabelecer uma previsão ou cálculo, mas apenas aproximações. Nesse sentido, a incerteza ou os riscos não são assumidos nem como externalidades nem como passíveis de serem absolutamente eliminados. Trata-se muito mais de considerar as incertezas e riscos como constitutivos do processo de desenvolvimento das ações, portanto devem ser assumidos nos procedimentos de planejamento e gestão de projetos. Uma das maneiras para que isso seja possível é a adoção de métodos e instrumentos mais flexíveis, abertos, que permitam aos gestores efetivar adaptações, modificações, replanejamento das atividades, resultados esperados, por exemplo, durante o próprio processo de instituição de um projeto.

\section{SISTEMAS COMPLEXOS E A DEFINIÇÃO DAS UNIDADES DE PLANEJAMENTO E GESTÃO DE PROJETOS}

A abordagem sistêmica veio contribuir para a construção de novos pontos de vista para tratar a relação sociedade e natureza, como sistemas abertos e complexos. Dessa forma, abriu caminho para que nas ciências agrárias, por exemplo, se desenvolvesse a abordagem dos sistemas agrários ou de sistemas de produção muito utilizados para as análises das trajetórias de unidades familiares de produção, dos agroecossistemas ou mesmo do desenvolvimento de regiões rurais. Nessa abordagem, o sistema produtivo ou agrário como uma totalidade organizada é coproduzido tanto pela interação entre humanos e natureza, bem como das relações sociais que são parte dele. Por isso metodologicamente procura-se analisar todas as atividades e os agentes do sistema, assim como as interações do agroecossistema. A partir desse trabalho é possível evidenciar os processos de diferenciação dos atores que integram esses sistemas (em tipologias), permitindo um tratamento diferenciado, caso essa análise seja utilizada como referência em ações de intervenção. Em suma, trata-se de uma abordagem que permite analisar, planejar e intervir tendo como unidade básica uma totalidade socioespacial dinâmica, constituída historicamente (MIGUEL, 2010; SILVA NETO, 2004).

Interessante observar que esses modelos foram ampliados para analisar e subsidiar projetos não somente em sistemas agrários, mas em sistemas pesqueiros (COTRIN; MIGUEL, 2009) e sistemas extrativistas (SILVA; MIGUEL, 2014), sistemas agroalimentares locais (MUCHNIK, 2006) ou ainda arranjos produtivos locais (BASSO, 2000). Nesses casos o sistema tem como base um determinado segmento ou conjunto de segmentos 
produtivos, que passam a ser compreendidos como totalidades formadas por elementos que interagem e ao mesmo tempo são sistemas que embora organizados, estabelecem fluxos com outros sistemas do seu entorno. Sua importância foi tão expressiva que disciplinas foram incorporadas aos cursos de Graduação e Pós-Graduação, entendendo que os profissionais deveriam ser capacitados e estarem munidos de ferramentas para trabalhar em campo com a visão sistêmica (SILVA NETO, 2004).

Ainda assim, Basso, Delgado e Silva Neto (2003) constatam que, embora a abordagem tenha uma unidade territorial como totalidade, sua ênfase está associada ao conjunto das atividades produtivas, fazendo com que a intervenção se direcione para o fortalecimento da capacidade produtiva dos diferentes grupos sociais que integram a unidade. Com efeito, pode acentuar a preocupação com as relações econômicas restritas à unidade básica tomada como sistema. É nesse sentido que os autores propõem a complementação com as abordagens das capacitações e do acesso aos ativos territoriais. Nessa abordagem, os diferentes atores sociais (famílias, comunidades, grupos) de um território são a unidade básica, a partir da qual procura-se compreender suas estratégias de reprodução social e, assim, intervir na ampliação das possibilidades e escolhas para sua efetivação.

A adoção da perspectiva sistêmica em planejamento e gestão de projetos pode ser observada não somente a partir dos modelos sistemas agrários ou produtivos. A emergência das abordagens sobre o desenvolvimento que enfatizam o endógeno e o local, também assumiram a visão sistêmica para modulação de novas unidades de planejamento e gestão de projetos voltados para o "desenvolvimento local sustentável" (BUARQUE, 1999). Nessas experiências, os municípios foram assumidos como unidades básicas, sendo incentivados a mobilizar os atores sociais locais para construir os Planos de Desenvolvimento Municipais. Esses planos foram elaborados a partir de uma visão sistêmica, procurando contemplar a complexidade da realidade nas múltiplas dimensões do desenvolvimento no território municipal. A experiência vigorou no Brasil entre 1997 e 2005 e foi fomentada na maioria dos municípios gaúchos.

Nesse mesmo período, organizações da sociedade civil e da administração pública assumiram, para fins do planejamento e execução de programas e projetos, as comunidades (rurais e urbanas) como unidades básicas para a intervenção. As comunidades eram reconhecidas como subunidades, cujas interações, problemas e proposições eram agregados às demais e faziam sentido diante da totalidade do município. Os planos serviam como base para a gestão de projetos, programas ou políticas, mobilizados e articulados no âmbito municipal. Se o plano tinha como uma das suas estratégias o desenvolvimento do turismo, por exemplo, sua efetivação (em termos de atividades, resultados, efeitos) deveria considerar as interações de todos os atores, recursos e características que davam sentido à organização no âmbito do território municipal.

A emergência da questão socioambiental justifica diversos projetos, programas e políticas direcionadas à preservação ambiental com o apoio das comunidades que dependem desses recursos. Para tal, também estabeleceu novas delimitações para o planejamento e gestão baseadas na visão sistêmica. Uma das experiências, ainda existente, é a dos Comitês das Bacias Hidrográficas, os quais assumem gestão descentralizada dos recursos hídricos, tomando uma (micro) bacia hidrográfica como uma nova unidade territorializada de planejamento e gestão de projetos. Cada comitê elabora um diagnós- 
tico e planejamento, tendo como pano de fundo a visão sistêmica (a bacia hidrográfica como totalidade). Desses planos e dos problemas identificados, foram produzidos vários projetos, muitos dos quais não geridos diretamente pelo comitê, mas por organizações parceiras que atuavam na temática socioambiental. Nesse sentido, os comitês de bacias acompanham a gestão dos projetos, dando atenção a seus resultados e efeitos, ainda que específicos (como recuperar a mata ciliar, por exemplo) em relação ao conjunto dos elementos que compõem a bacia.

Em outro caso, uma perspectiva sistêmica foi adotada para o desenvolvimento sustentável de comunidades rurais e programas de combate à pobreza (BACELAR, 2009). Assentamentos de reforma agrária, comunidades tradicionais, também foram delimitados como unidades básicas a partir das quais foram elaborados planos participativos, adotando ferramentas e procedimentos que assumiam a comunidade, o assentamento e a reserva extrativista como unidades básicas de diagnóstico, planejamento de ações e criação de projetos.

Ainda que muitas delas vinculadas a áreas temáticas ou programas governamentais específicos, essas experiências assumem uma dada configuração socioespacial, como unidade básica, de promover ações em prol do desenvolvimento.

Vários autores, contudo, chamaram atenção para as limitações da adoção dessas unidades básicas em âmbito local - como comunidades, assentamentos rurais, municípios, sistemas produtivos, municípios, bacias hidrográficas, reservas extrativistas, arranjos produtivos locais - que, muitas vezes, foram assumidos como unidades autócnes, capazes de produzir mudanças ou "se desenvolver" somente mobilizando os recursos internos ao próprio sistema (GUIMARÃES NETO, 2010; BACELAR, 2009). Ao fazê-lo, davam pouca importância para o ambiente "externo" no qual as unidades locais estavam inseridas, assim como aos fluxos - de entradas e saídas (recursos materiais e financeiros, energias, pessoas) - com outros sistemas ou totalidades. Os mesmos autores também observam que, ao delimitar um município, ou comunidade, e assumi-lo como unidade de planejamento ou gestão de projetos, muitas vezes como um procedimento imposto aos atores locais, passa-se a considerar aquela nova unidade básica como uma totalidade homogênea, negligenciando as diferenças e hierarquias entre atores, processos e interações internas. Ainda que um sistema é uma totalidade organizada, é preciso considerar sua interação com outros sistemas (ou subsistemas) e seu lugar nessa hierarquia, bem como as tensões entre os atores que, comumente, atravessam os âmbitos interno e externo.

A visão sistêmica trouxe grande contribuição para pensar o desenvolvimento regional em sua complexidade, na medida em que o território passa a ser assumido como unidade básica para análise, planejamento e intervenção, e não, isoladamente, um setor produtivo ou dimensão unilinear (econômica, social, ambiental). A própria definição de território, que orienta muitos procedimentos em planejamento e gestão de projetos de desenvolvimento regional, assume o território constituído A partir dessa visão, um território, ainda que possua definições diversas, é assumido como unidade de planejamento e gestão de projetos; trata-se de um sistema com uma totalidade mais ou menos organizada, composta por subsistemas, elementos, canais de interação e hierarquias, que possui uma dinâmica construída historicamente pela ação social (CARRIÈRE; CAZELA, 2006; DESCONSI, 2018). A visão sistêmica, quando assumida adequadamente em 
seus pressupostos e princípios já assinados nesse texto, permite compreender e planejar o desenvolvimento das regiões, considerando essas como partes de uma totalidade maior, como o território estadual ou nacional.

\section{COMPLEXIDADE E ADEQUAÇÕES NAS PRÁTICAS DE GESTÃO DE PROJETOS E PLANEJAMENTO}

Diante do exposto até agora, essa seção dedica-se à reflexão de como, do ponto de vista prático, estão sendo construídas soluções que permitam não abdicar dos procedimentos racionais que constituem os procedimentos comuns em planejamento e gestão de projetos, mas, ao mesmo tempo, considerá-los como processos de intervenção que, necessariamente, ocorrem em sistemas complexos.

Segundo a literatura especializada, um projeto pode ser definido como uma ação social organizada, estruturada em objetivos, resultados e atividades, considerando-se uma quantidade limitada de recursos (materiais, humanos, financeiros) em um tempo determinado. Nessa definição o projeto é um instrumento focalizado em unidades de intervenção concretas. Um projeto raramente é um empreendimento isolado (DESCON$\mathrm{SI}, 2018)$. De modo geral, está vinculado à programas e políticas definidas pelo setor público ou privado, ao menos segue seus objetivos e eixos estratégicos de ação muitas vezes integrante do planejamento. Fazendo uma interface com as discussões sobre os sistemas complexos, pode-se afirmar que um projeto se trata de uma intervenção sobre alguns elementos específicos do sistema, modificando fluxos e interação.

No âmbito mais específico da gestão de projetos, há dois movimentos importantes associados às contribuições da perspectiva sistêmica que podem ser assinalados. O primeiro é relativo à adoção da visão sistêmica como pressuposto para a gestão do ciclo de um projeto. O Marco Lógico, uma das metodologias de planejamento de projetos mais utilizadas pelas organizações da sociedade civil ainda hoje, foi formulado tendo como base a perspectiva analítica. Não por acaso o encadeamento entre atividades, metas, resultados e impactos é linear e está baseado no princípio da relação entre causa-efeito. Supõe o controle de todas as etapas do processo de realização do projeto. 0 Marco Lógico atualmente, no entanto, foi adaptado e complementado para permitir seu uso em sistemas complexos, sendo complementado por metodologias que asseguram a participação dos atores durante todo o processo. Reconhecendo que a realidade em que são planejados os projetos são sistemas complexos, entende-se que é preciso compreender e apreender suficientemente a mesma com o auxílio de outras metodologias para, em seguida, "sistematizar a complexidade". Ou seja, efetuar a tradução da complexidade em instrumento que assegura a aplicabilidade das ações planejadas (PFEIFER, 2010; GTZ, 1998).

O segundo movimento refere-se à relação do projeto propriamente dito com o ambiente, no contexto com o sistema complexo no qual se quer intervir. Nas recomendações da elaboração de projetos fica clara a importância atribuída à capacidade dos mesmos em gerar mudanças em uma realidade mais ampla. Isso pode ser observado nas orientações para definição dos impactos esperados. Os impactos referem-se às mudanças que o projeto gerou ou pode gerar no contexto onde foi aplicado, não somente nos beneficiários diretos, mas na unidade sistêmica de abrangência (FAO, 2012). Esse aspecto requer como complementar um planejamento sistêmico não restrito ao projeto 
propriamente dito, definindo o ponto de partida da ação e monitorando a avaliação do projeto em relação a uma totalidade mais ampla. Planejar e executar projetos isoladamente em um dado contexto, com etapas descontínuas, sem o envolvimento ativo dos beneficiários e parceiros, ou mesmo das equipes responsáveis, significa estabelecer as condições para a baixa efetividade (PFEIFER, 2010; GTZ, 1998). Por outro lado, talvez se adotada uma perspectiva analítica, o resultado do projeto pode ter representado certo êxito por desenvolver suas atividades, resultados e efeitos esperados, na medida em que estes desconsideram ou dão pouca importância para o entorno do projeto.

Nas subseções a seguir, apresenta-se dois casos aplicados de adequação dos procedimentos: o primeiro tratando do confronto entre as concepções de técnicos/agentes bancários e os agricultores do Nordeste no planejamento e execução de projetos de crédito rural, e o segundo relativo ao uso do Marco Lógico em sistemas complexos.

\section{O Confronto com as Racionalidades dos Atores Sociais: projetos de crédito rural}

O paradigma da complexidade e as teorias derivadas inspiram a construção de diversas abordagens teórico-metodológicas, cuja contribuição primeira foi relativizar ou trazer à tona outras formas de apreender a realidade e sugerir intervenção sobre ela (SILVA NETO; BASSO, 2010). Nesse caminho, a reconsideração dos saberes tradicionais, não validados pela ciência analítica e, obviamente, dos atores que dispunham dos mesmos, torna-se um material fundamental para questionar a universalidade da própria ciência e dos profissionais que a difundem. Desde a década de 60 do século 20 em diante, quando as organizações internacionais passaram a apoiar projetos de desenvolvimento, muitas de suas justificativas assumiam a perspectiva da racionalização das práticas das populações como meio para superar outras visões de mundo, modos de produzir e viver, comumente classificados como irracionais (GEERTZ, 1997). Ao assumir-se como conhecimento da sociedade mais avançado em relação aos demais, a racionalidade científica colaborava para fundamentar uma visão unilinear do desenvolvimento, modulado "de cima para baixo", afinal, não adiantaria conhecer outras visões de mundo e modos de vida a não ser como meio para melhor superação do mesmo.

A valorização das escalas locais e de abordagens participativas no processo de planejamento e gestão de projetos, colocou em evidência diferentes percepções dos atores sobre os problemas e as possíveis estratégias a serem adotadas para seu enfrentamento. Questiona-se, assim, em que medida esse conhecimento prático dos atores deve ou não ser valorizado em detrimento das análises e soluções ponderadas pelos técnicos, gestores que assumem a racionalidade da ciência. Não é de hoje que há uma crítica à superioridade e à universalidade do conhecimento científico em relação às demais formas de conhecimento, muitas vezes classificadas como irracionais pelos especialistas. Godelier (1965) já ponderava que as comunidades camponesas dispunham de uma racionalidade econômica própria, pois levava em consideração formas específicas de cálculo e de previsão que orientavam suas ações, visando um futuro melhor. Tais formas, contudo, não eram condizentes com a racionalidade informada pelos economistas, agrônomos e administradores. Nesses termos, há várias racionalidades em questão, produtos de construção das disposições mentais dos atores. No contato entre os técnicos que vão coordenar o planejamento e gestão de projetos, essas práticas ficam evidentes. 
Reconhecer que existem diferentes formas de conhecimento, ou ainda diversos modos de apropriação dos saberes, inclusive do saber científico, é também reconhecer a existência de distintas racionalidades e que todas elas são limitadas. Pensando que o processo de planejamento e gestão de projetos é constituído de um conjunto de concepções, procedimentos e técnicas que, articuladas, visam a mobilizar atores sociais para promover mudanças, superar problemas, concretizar anseios, seu processo deve permitir a aprendizagem e o aprimoramento da interação dos atores envolvidos. Embora focados em resultados ou objetivos, o processo de desenvolvimento de um projeto deve oportunizar espaços para promover o desenvolvimento de capacidades e a melhoria das condições de possibilidade de escolha para o conjunto da população.

Essa discussão aparece no trabalho de Desconsi e Pacífico (2016) sobre impactos de projetos de microcrédito rural entre os agricultores familiares do Nordeste. Nesse estudo, os autores constatam que os procedimentos de gestão de projetos do crédito rural, utilizados por técnicos e agentes bancários, possuem uma lógica linear focada em uma atividade produtiva somente. Sobre ela, os profissionais constroem uma previsão, um resultado esperado associado ao aumento da produção, levando-se em consideração conhecimento técnico especializado associado à atividade do projeto. É sobre essa atividade estritamente, e do caminho traçado nas planilhas dos projetos, que estabelecem o monitoramento e avaliação dos projetos. Essa lógica racional, contudo, não é a mesma da maioria dos agricultores familiares, ainda que ambas as partes tenham consenso sobre a atividade e os itens que devem ser objeto do projeto. Isso porque os agricultores levam em consideração a "entrada do projeto" dentro de suas estratégias familiares de produção, as quais, muitas vezes, não são restritas a uma unidade de produção agrícola. O exemplo dos projetos para compra de gado bovino é ilustrativo. Os animais não são somente um meio de produção, mas também são a poupança da família e a própria possibilidade de garantir o reembolso do financiamento, portanto pode se optar em vendê-lo, trocá-lo ou converter o mesmo em outro recurso produtivo em um curto período de tempo.

Nesse sentido, o planejamento e a operacionalização dos projetos de microcrédito rural são marcados por uma racionalidade distinta dos agricultores que parecem orientados pela complexidade das estratégias familiares, não restritas ao cálculo e à previsibilidade da ciência agronômica e econômica. O caso demonstra um confronto entre distintas racionalidades dos atores, expressas em convergências e divergências no ciclo de vida de um projeto. Sobre esse exemplo, os autores observam que muitos técnicos e agentes bancários locais que conheciam as práticas dos agricultores, efetivam movimentos constantes de tradução e mediação de mão dupla: de um lado, fazendo os agricultores compreenderem a lógica implícita nas planilhas bancárias; de outro, traduzindo e procurando sintetizar a complexidade da racionalidade dos agricultores nas planilhas bancárias, no monitoramento e na avaliação dos projetos (DESCONSI, 2018). Fica claro que não se trata de complexificar as planilhas bancárias - instrumentos - de modo a que estas passem a registrar e permitir o controle de todos as interações e elementos dos sistemas familiares dos agricultores, como defendem alguns gestores. Trata-se muito mais de mudança na relação entre técnicos e agricultores e adoção de alguns ajustes para tornar os instrumentos mais flexíveis e abertos do ponto de vista da gestão. 


\section{O Marco Lógico \\ - adaptações para o trabalho em sistemas complexos}

O exemplo do marco lógico é plausível para essa reflexão (ARMANI, 2004; PFEIFER, 2010). Trata-se de um instrumento construído para dar racionalidade e permitir maior controle na gestão dos projetos de desenvolvimento ainda da década de 60. Sua estrutura tem como base uma relação causa e efeito do encadeamento vertical - atividades, resultado, objetivos e efeitos - e horizontal - resultados, marco zero, indicadores, fontes de verificação e suposições. Trata-se de um instrumento focado em resultados, objetivo que articula e hierarquiza cada uma das etapas (meios) para alcançar determinados fins. Nesse sentido, é um instrumento lógico-racional construído sobre a base do paradigma analítico da ciência, predominante até o século 20. Contraditoriamente, até recentemente o marco lógico ainda é um dos instrumentos mais utilizados para o planejamento e gestão de projetos, reconhecidos pelos organismos internacionais como modelo de elaboração e base para o monitoramento e a avaliação, apropriados pelas ONGs e agentes do serviço público, objeto de cursos de capacitação e assim por diante.

Sua pertinência, enquanto instrumento, ocorre nos dias atuais quando: i) há um reconhecimento entre os profissionais das várias áreas do conhecimento de que o planejamento e a gestão de projetos ocorrem em sistemas complexos; ii) quando as novas abordagens sobre o desenvolvimento sustentável acentuam a ênfase no território, na heterogeneidade dos atores e sua participação no processo, além de chamar atenção para a interdependência entre as múltiplas dimensões (econômica, social, ambiental, política, cultural, histórica); iii) quando há um reconhecimento dos fatores externos ao projeto inscritos no ambiente, apontando para a impossibilidade de gerir plenamente todas as variáveis existentes que podem afetar um projeto.

Efetivamente, o Marco Lógico subsiste, por um lado, pela necessidade de que o planejamento e a gestão de projetos possuem instrumentos racionais e objetivos para dar efetividade às ações propostas. Por outro lado, isso não ocorreria se tal instrumento não fosse adaptado para intervir em sistemas complexos. A adaptação aqui referida pode ser apresentada de diversas maneiras, mas, para fins de compreensão nesse texto, assinalam-se algumas adequações, algumas associadas a modificações no escopo do Marco Lógico e outras relativas ao caráter de complementaridade do mesmo com outras metodologias e instrumentos.

i) Concepção sobre os efeitos ou impactos do projeto: em todos os manuais e indicações, os chamados "efeitos" são referentes a mudanças esperadas e previstas que estão para além dos atores diretamente envolvidos no projeto. Dito de outra maneira, é a perspectiva de que o projeto deve provocar mudanças no ambiente onde foi planejado e instalado. Ao fazê-lo, o instrumento acentua seu caráter objetivo e focado em um determinado problema ou anseio, mas, ao mesmo tempo, aberto, por prever que seus efeitos podem ou devem provocar mudanças nos comportamentos, nas práticas ou numa linguagem utilizada pela visão sistêmica - mudanças nas interações e jogos de forças configuradas no ambiente. Tal abertura exige que a gestão do projeto, sobretudo na fase de avaliação, adote procedimentos de verificação dessas mudanças considerando um sistema ou território onde o projeto foi instituído (FAO, 2012). 
ii) Inclusão da coluna "marco zero" ou "ponto de partida": algumas organizações incluem uma coluna vertical adicional no Marco Lógico para registro preciso do ponto de partida do projeto em relação às atividades, às metas, aos resultados e aos efeitos previstos. Se essa informação permite aprimorar os procedimentos de gestão do projeto, ela também tem como objetivo deixar claro que o projeto está inserido em um contexto mais amplo, o qual pode, inclusive, ter sido objeto de outros projetos similares ou que se complementam. O ponto de partida demarca o lugar das ações do projeto dentro da complexidade do sistema em que está sendo proposto (FAO, 2012).

iii) O Marco Lógico complementado com outras metodologias de planejamento: isso pode ser identificado por dois exemplos. Na fase de planejamento do projeto ou de planejamento territorial, quando se definem as linhas estratégicas de ação, utilizam-se outras metodologias que permitam a participação efetiva dos diversos atores na análise dos problemas, a análise dos atores, a definição e hierarquização dos principais problemas a serem enfrentados e as respectivas estratégias. Essas metodologias são assumidas antes e durante o planejamento de um projeto propriamente dito, utilizando o instrumento do Marco Lógico. A metodologia "planejamento orientado para objetivos", construída pela GTZ (1998) ou pela FAO (2012), complementa o Marco Lógico inovando em metodologias que assegurem a participação. Se a participação funciona, as decisões são compreendidas e compartilhadas e há mais chances de os atores assumirem compromisso com o projeto (PFEIFER, 2010). Nesse sentido, não é o instrumento do marco lógico que se complexifica para dar conta da realidade complexa; são outras metodologias que permitem captar informações, refletir, envolver os atores para, então, sistematizar as ações planejadas no escopo possível de ser trabalhado. O manual da GTZ (1998) chama atenção para a capacidade de, depois de conhecer a complexidade do contexto, "sistematizar a complexidade" para poder intervir sobre alguns de seus elementos e modificar estruturas ou fluxos ali existentes.

iv) O Marco Lógico e as metodologias de promoção da aprendizagem: a partir das teorias da complexidade sugere-se que o processo de aprendizagem é fundamental para a produção de mudanças mais duradouras nos sistemas. Nesse sentido, consideram que não há um rumo totalmente previsível e calculável da evolução do sistema. Por essa via, valoriza-se a construção do conhecimento com um processo coletivo, envolvendo saber científico e não científico, tendo como base a própria experiências. Logo, Armani (2004), observando a experiências das ONGs com o marco lógico, sugere fortemente a adoção das metodologias participativas que permitam aprimorar o aprendizado na gestão de projetos. Duas sugestões parecem interessantes. Uma delas se refere à sistematização de experiências; tal metodologia é muito utilizada pelos movimentos sociais e ONGs enquanto recurso para registrar, a partir dos próprios atores, como foram os resultados e limites das experiências. A segunda é a adoção de intercâmbios entre os atores envolvidos ou interessados em um dado tipo de solução, que será transformada em projeto, e outros atores, que já executaram projetos similares. Tanto em um como em outro caso, são metodologias que podem complementar o instrumento do marco lógico visando a uma meIhor adequação à realidade específica e potencializar os possíveis efeitos do projeto (CHAVEZ-TAFUR, 2007). 


\section{À GUISA DE CONCLUSÃO}

O texto apresentou, ainda que de forma breve, as principais características do paradigma (ou teorias) da complexidade em relação ao paradigma analítico predominante até décadas recentes na ciência. Pode-se destacar a ênfase nos processos de interação e a diversidade dos elementos que compõem sistemas sociais, econômicos, ecológicos, por exemplo, os quais apresentam alta dinamicidade. O reconhecimento da complexidade dos sistemas aponta os limites da própria ciência e seus aportes teóricos e metodológicos para dar conta da complexidade. Ao mesmo tempo, assume-se que a ciência sempre terá capacidade limitada de apreender a complexidade da realidade, portanto não tem condições de controlar todas as variáveis possíveis dos sistemas complexos. Não se pode prever e calcular plenamente a evolução e a dinâmica dos sistemas. Quando essa perspectiva é assumida nas abordagens do desenvolvimento e no processo de planejamento e gestão de projetos, pode-se afirmar que não é possível prever o estilo de desenvolvimento a ser construído por uma determinada sociedade ou território. Os procedimentos utilizados na intervenção passam à gestão (e não o controle pleno) das incertezas e riscos que acompanham as ações, assim como compreendem as ações dos atores sociais na construção das trajetórias de desenvolvimento.

É neste sentido que a teoria dos sistemas influenciou diretamente na adequação e criação de metodologias e ferramentas utilizadas no planejamento e gestão de projetos. Uma de suas principais adequações assentou-se na definição de unidades de análise e intervenção (sistemas produtivos, territórios, bacias hidrográficas, redes de cooperação), como totalidades formadas por interações entre elementos sociais, econômicos, políticos e espaciais, as quais (re) produzem fluxos internos e externos, não sendo estáticos. Um projeto compreende, assim, um conjunto de ações específicas que incidem sobre alguns dos elementos e interações de um sistema complexo, e podem produzir efeitos (nem sempre previsíveis e calculáveis) mais amplos nas unidades em questão.

Nos exemplos expostos na terceira seção, constata-se que há possibilidades de adequar e complementar os procedimentos racionais convencionais utilizados em planejamento e gestão de projetos. Isso implica poder ser operado como no exemplo do marco lógico, cujos procedimentos foram adequados e complementados para dar conta de sistemas complexos, como também houve mudança na relação entre técnicos e gestores e o público beneficiário dos projetos. Tanto em um quanto em outro caso, o reconhecimento da complexidade dos sistemas que são o ambiente das ações de intervenção, exigem que o planejamento e a gestão de projetos sejam modulados e adaptados às especificidades desses sistemas, sobretudo quando este tem como base a escala local.

A racionalidade segue sendo um princípio importante no planejamento e na gestão de projetos, pois ela permite a concretização de ações visando à solução de problemas e alcançando resultados e objetivos. Essa ação, entretanto, precisa ser situada na complexidade dos sistemas objetos de intervenção, exigindo a mobilização de vários instrumentos de análise, considerando a percepção dos atores e as interações que integram. Ademais, o processo de planejamento e gestão de projetos deve permitir a construção da aprendizagem entre os atores envolvidos e a produção do conhecimento a partir da própria experiências, colocando em interface o saber científico e o local. 


\section{REFERÊNCIAS}

ARMANI, D. Como elaborar projetos sociais? Porto Alegre: Tomo Editorial, 2004.

BACELAR, T. Gestão social e desenvolvimento sustentável dos territórios, o desafio da multidimensionalidade: uma visão a partir do Brasil. In: BACELAR, T. et al. (org.). Gestão social dos territórios. Brasília: IICA, 2009. p. 35-52. Vol. 10. (Série DRS).

BASSO, D. (org.). Estudo da dinâmica e perspectivas da indústria de ljuí-RS. Ijuí: Ed. Unijuí, 2000.

BASSO, D.; DELGADO, N.; SILVA NETO, B. Incertezas e racionalidades em ações de desenvolvimento local. Desenvolvimento em Questão, ljuí, ano 1, vol. 1, p. 73-105, 2003.

BENTALANFFY, L. V. Teoría general de los sistemas: fundamentos, desarrollo, aplicaciones. 7. ed. México: Fundo de Cultura Mexicana, 1976.

BUARQUE, S. Metodologia e planejamento do desenvolvimento local e municipal sustentável. Brasília: IICA, 1999.

CARRIÈRE J. P.; CAZELLA, A. Abordagem introdutória do conceito de desenvolvimento territorial. Revista Eisforia, Florianópolis: CCA; UFSC, n. 4, p. 23-47, 2006.

CHAVEZ-TAFUR, J. Aprendendo com a prática: uma metodologia para sistematização de experiências. Rio de Janeiro: Aspta, 2007.

COTRIM, D.; MIGUEL, L. Renda da pesca artesanal: Análise dos sistemas de produção na pesca em Tramandaí - RS. Redes, Santa Cruz do Sul, v. 14, n. 3, p. 5-23, set./dez. 2009.

DESCONSI, C. Planejamento, gestão e execução de projetos; uma arena de conflitos entre redes de atores. Chapecó, Revisa Grifos, ano 27, n. 44, p. 71-91, 2018.

DESCONSI, C.; PACÍFICO, D. Apropriação do microcrédito rural no Nordeste brasileiro: o papel dos animais no sistema produtivo e econômico das famílias no agreste pernambucano. Revista Ideas, Rio de Janeiro, vol. 8, n. 2, p. 104-134, 2016.

FAO. Organização das Nações Unidas para a Alimentação e a Agricultura. Manual metodológico de monitoreo y avaluación de Proyectos Metodologia SIMMER. Madri, España: FAO, 2012.

GEERTZ, C. O saber local: novos ensaios em antropologia interpretativa. Petrópolis, RJ: Vozes, 1997.

GTZ. German Tecnical Cooperation Agency. Planejamento orientado para objetivos. Guia técnico. Brasília: GTZ, 1998.

GODELIER, M. Objet e méthodes et l'antrophologieéconomique. L'home, Paris, Tomo 5, vol. 2, 1965.

GUIMARÃES NETO, L. Antecedentes e evolução do planejamento territorial no Brasil. In: FAVARETO, A. et al. (org.). Políticas de desenvolvimento rural: avanços e desafios. Brasília: IICA, 2010, p. 47-80. (Série DRS). MIGUEL, L. A. Dinâmica e diferenciação de sistemas agrários. Porto Alegre: Plageder; Ed. UFRGS, 2010.

MUCHNIK, J. Sistemas agroalimentarios localizados: evolución del concepto y diversidad de situaciones. CONGRESO INTERNACIONAL DE LA RED SIAL, 3., 2006, Baeza, España. Analles [...]. Baeza, España, 2006.

PFEIFER, P. Quadro Lógico um método para planejar e gerenciar mudanças. Revista do Serviço Público, Brasília: Escola Nacional de Administração Pública, ano 51, vol. 1, p. 81-122, 2010.

PRIGOGINE, I. O fim das certezas: tempo, caos e as leis da natureza. São Paulo: Unesp, 1996.

SEPUELVEDA, S. Desenvolvimento microrregional sustentável: métodos para planejamento. Brasília: IICA, 2005.

SILVA NETO, B. Complexidade e desenvolvimento. Desenvolvimento em Questão. Ijuí: Ed Unijuí, v. 2, n. 4, p. 9-32, 2004.

SILVA NETO, B.; BASSO, D. A ciência e o desenvolvimento sustentável: para além do positivismo e da pós-modernidade. Ambiente \& Sociedade, Campinas, n. 23, vol. 2, p. 315-329, 2010.

SILVA, C. V.; MIGUEL, L. Extrativismo e visão sistêmica. Novos Cadernos Naea, v. 17, n. 2, p 189-217, 2014. 